\title{
Perspective on Canaletto's Paintings of Piazza San Marco in Venice
}

\author{
Casper J. Erkelens \\ Experimental Psychology, Helmholtz Institute, Utrecht University, Utrecht, The Netherlands
}

Received 21 June 2019; accepted 18 December 2019

\begin{abstract}
Perspective plays an important role in the creation and appreciation of depth on paper and canvas. Paintings of extant scenes are interesting objects for studying perspective, because such paintings provide insight into how painters apply different aspects of perspective in creating highly admired paintings. In this regard the paintings of the Piazza San Marco in Venice by Canaletto in the eighteenth century are of particular interest because of the Piazza's extraordinary geometry, and the fact that Canaletto produced a number of paintings from similar but not identical viewing positions throughout his career. Canaletto is generally regarded as a great master of linear perspective. Analysis of nine paintings shows that Canaletto almost perfectly constructed perspective lines and vanishing points in his paintings. Accurate reconstruction is virtually impossible from observation alone because of the irregular quadrilateral shape of the Piazza. Use of constructive tools is discussed. The geometry of Piazza San Marco is misjudged in three paintings, questioning their authenticity. Sizes of buildings and human figures deviate from the rules of linear perspective in many of the analysed paintings. Shadows are stereotypical in all and even impossible in two of the analysed paintings. The precise perspective lines and vanishing points in combination with the variety of sizes for buildings and human figures may provide insight in the employed production method and the perceptual experience of a given scene.
\end{abstract}

\section{Keywords}

Linear perspective, vanishing points, tools, Canaletto, Piazza San Marco

\section{Introduction}

Linear perspective is a method of creating the illusion of depth on a flat surface. A recent study showed that a number of famous painters, known for their

\footnotetext{
*To whom correspondence should be addressed. E-mail: c.j.erkelens@uu.nl 
expertise in linear perspective, applied linear perspective to direction but not distance in depth (Erkelens, 2016). Distances were painted as if the vanishing points in the painting represented a finite intersection point. A perspective space with such characteristics has been proposed as a model for visual space (Erkelens, 2015, 2017). Apparently, certain painters applied linear perspective relative to visual space rather than physical space. The consequence of applying this type of perspective is that these painters could not make use of optical projection tools.

Among the painters who applied this type of perspective were vedutisti, renowned for their expertise in linear perspective. Vedutisti are painters of highly detailed, usually large-scale cityscapes and architectural vistas (vedute). The style of painting was introduced in Italy in the late seventeenth century by Gaspare Vanvitelli, a Dutch painter born as Caspar van Wittel in Amersfoort in the Netherlands (Cursi, 2002; Kemp, 1990). Painters such as Giovanni Paolo Panini, Giovanni Battista Piranesi and Giovanni Antonio Canal, better known as Canaletto, are famous vedutisti. Their use of linear perspective relative to visual rather than physical space (Erkelens, 2016) questions claims that several vedutisti used the camera obscura and camera lucida for creating their masterpieces (Facos, 2011; Hockney, 2001; Kemp, 1990; Lüthy, 2005; Steadman, 2001). Canaletto is regarded as one of the painters who used an optical device. One indication, among others, is that Canaletto owned a camera obscura, which is currently exhibited at Museo Correr, located at the Piazza San Marco in Venice.

Canaletto (1697-1768), probably the greatest of vedutisti, painted precise views of Venetian architecture that are found in most of the world's major art museums (Baetjer and Links, 1989). He was professor of perspective at the Accademia of Venice and as such recognised as an authority on the topic. Since he took the liberty to deviate from the rules of traditional linear perspective with regard to distances in depth, it is interesting to scrutinise other aspects of perspective in his paintings of extant scenes. His paintings of Piazza San Marco are particularly suited for such a study. Over a period of more than 30 years, Canaletto painted Piazza San Marco in Venice a great number of times. Of these paintings, a considerable number was painted from viewpoints on the west side of the Piazza. Contemporaries and followers such as Bernardo Bellotto, Francesco Guardi, Giovanni Battista Cimaroli and Apollonio Domenichini painted the Piazza from similar viewpoints too. The paintings from these viewpoints are interesting because of the Piazza's extraordinary geometry. Generally, perspective paintings show one-point perspective, implying that lines parallel in depth meet in a single vanishing point on the horizon line. Sometimes, paintings show two-point perspective with two vanishing points located on the horizon. Then the vanishing points have positions that are usually far apart, often outside of the painting. Occasionally, artworks show three-point perspective, with a third vanishing point far above or below 
the horizon for all vertical lines. An example is the lithograph "Ascending and Descending" by the Dutch artist Maurits Escher. Three-point perspective is so exceptional in paintings that it is not treated in a standard work on linear perspective in art (Kemp, 1990). Canaletto's paintings belong to the class of one- and two-point perspective paintings in which vanishing points lie on the horizon and verticals are parallel. The extraordinary geometry of the Piazza San Marco, however, defines three vanishing points close to each other on the horizon. The geometry of the Piazza requires great skills and knowledge of the painter in order to accurately position perspective lines and vanishing points on the canvas. Perspective quality has been examined of nine of Canaletto's paintings of the Piazza San Marco. Analysis included the accuracy and precision of perspective lines, vanishing points as well as those of sizes and shadows of buildings and people.

\section{Layout of Piazza San Marco}

Figure 1 shows the floor plan of the Piazza San Marco and adjacent buildings. The layout of the Piazza is an irregular quadrilateral, implying that none of its boundaries are parallel to one another. It is virtually unchanged since the time of Canaletto. The analysed paintings depict the Piazza San Marco from viewpoints that are close to or in the buildings currently known as Ala Napoleonica (Napoleonic Wing) on the west side of the Piazza. Currently the Ala Napoleonica holds the entrance to the Museo Correr. In making sketches for the analysed paintings, Canaletto looked at the Basilica San Marco and the Campanile, i.e. the bell tower, in frontal view, and the two Procuratie and the Piazza oriented in depth. The connected buildings on the north side of the Piazza, called Procuratie Vecchie, are oriented in another direction than the buildings on the south side, called Procuratie Nuove. The angle between the two Procuratie is about $11^{\mathrm{o}}$. As a consequence, vanishing points for the left and right Procuratie should have different positions in photorealistic paintings. The two Procuratie are oriented in other directions than the long axis of a complex geometrical pavement design laid out by the Venetian architect Andrea Tirali in 1723. The angle between the Procuratie Vecchie and the geometric patterns is about $3^{\circ}$, whereas the angle between the geometric patterns and the Procuratie Nuove is about $8^{\circ}$. As a consequence, the vanishing point for the geometric patterns should be placed closer to the vanishing point for the Procuratie Vecchie than to that for the Procuratie Nuove in photorealistic paintings. From the viewpoint of the red dot, the vanishing point for the geometric patterns lies on the north side of the Basilica's central arch. If the viewpoint is shifted along the Ala Napoleonica, the three vanishing point shift by equal distances in the same direction in the painting. The three flagpoles in front of the Basilica have special positions in the geometric patterns. The outer flagpoles are placed at the centres of the left and right patterns and the middle 




Figure 1. Floor plan of Piazza San Marco. The red dot marks the position in the Ala Napoleonica that lies on the axis of the geometric patterns on the pavement of the Piazza. Canaletto depicted the Piazza from about this position. Solid arrows of lines parallel to the Procuratie Vecchie (open arrow), geometric patterns, and the Procuratie Nuove (open double arrow), point to positions on the Basilica that are vanishing points in pictures taken from the red dot. Orange dots mark the flagpoles. The compass rose indicates the orientation of the Piazza. The aerial view of the Piazza is copied from the Google site https://www.google.it/maps/@ 45 $.4338801,12.3385282,19 \mathrm{z}$.

flagpole is placed on the central axis of the patterns. If a picture is taken from the red dot, the middle flagpole lies on the north side of the central arch of the Basilica. The flagpoles shift relative to the Basilica if the viewpoint is shifted along the Ala Napoleonica. Viewpoint and flagpoles shift in opposite directions. Thus, both the positions of the vanishing points and the flagpoles provide information about the viewpoint. Both sources of information should be consistent in photorealistic paintings.

Figure 2 shows a photograph taken from a position that is close to positions used by Canaletto. The picture shows added perspective lines along both Procuratie and the pavement, meeting in three vanishing points. The vanishing points are positioned on the horizon at eye level for a person standing on the pavement, which is notably lower than in any of Canaletto's paintings. The middle vanishing point lies on the north side of the central arch of the Basilica, 


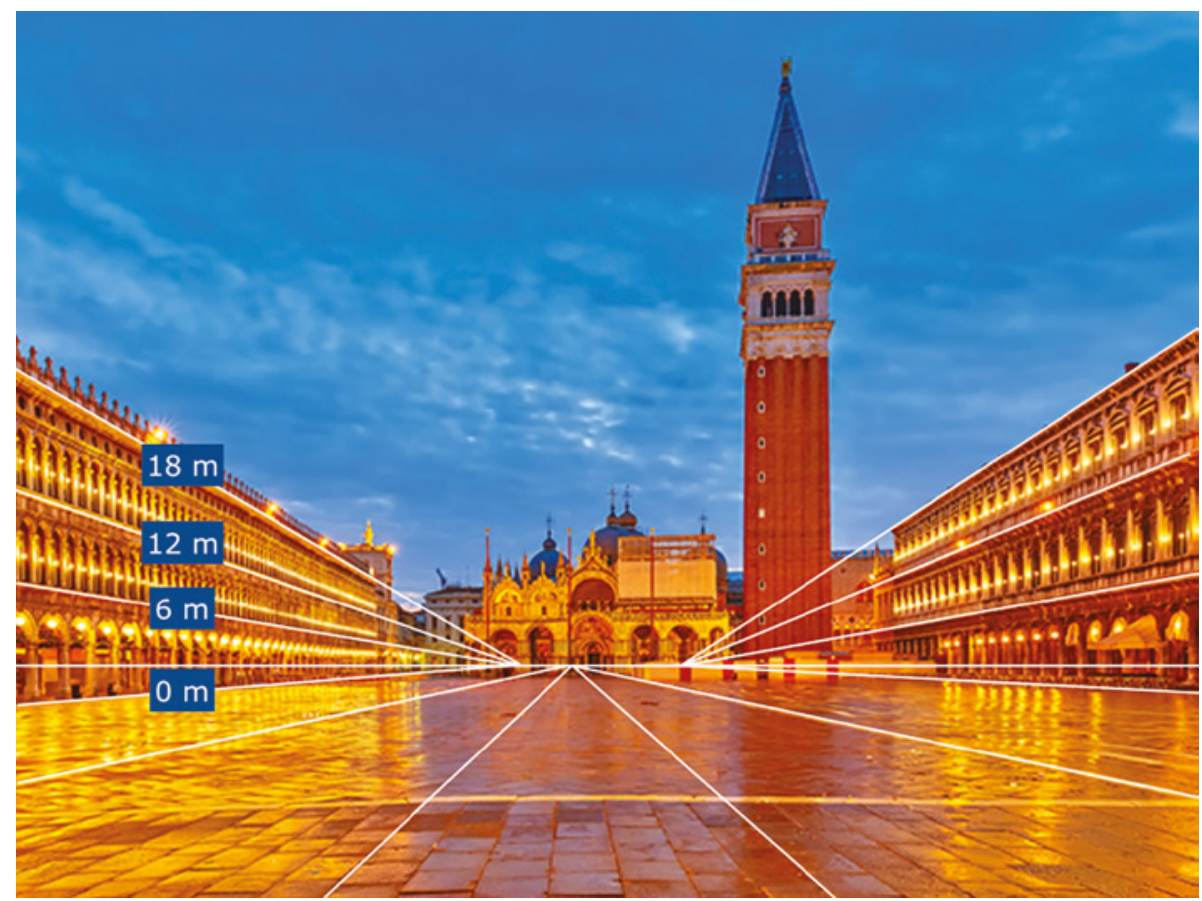

Figure 2. View on of an empty and wet Piazza San Marco. The picture is taken in front of Ala Napoleonica close to positions used by Canaletto. White lines indicate perspective lines converging in the three vanishing points. Indicated heights on the buildings of Procuratie Vecchie have been used as reference for sizes of the central arch of the Basilica (24 m) and the Campanile (99 m) in Canaletto's paintings.

indicating that the camera in Fig. 2 was close to the axis of the geometric patterns. The middle flagpole is imaged on the north side of the central arch too, which is consistent with the assumed camera position. Figure 2 also shows the asymmetric distribution of the vanishing points. Note that the flagpoles are about equally tall as the central arch, including the statue of San Marco. Heights of floors of the buildings along the Procuratie Vecchie have been used as references for judging sizes of the Campanile, the Basilica and the human figures present on the Piazza in Canaletto's paintings. The height of the central arch, including the statue of San Marco, has been taken as a measure for the size of the Basilica San Marco.

\section{Analysis of Perspective Lines, Vanishing Points and Sizes}

Figure 3 shows thumbnail images of the nine paintings analysed in this study. The paintings are ranked from best (1) to worst (9) in number of vanishing points and precision of perspective lines. The images may not be accurate 


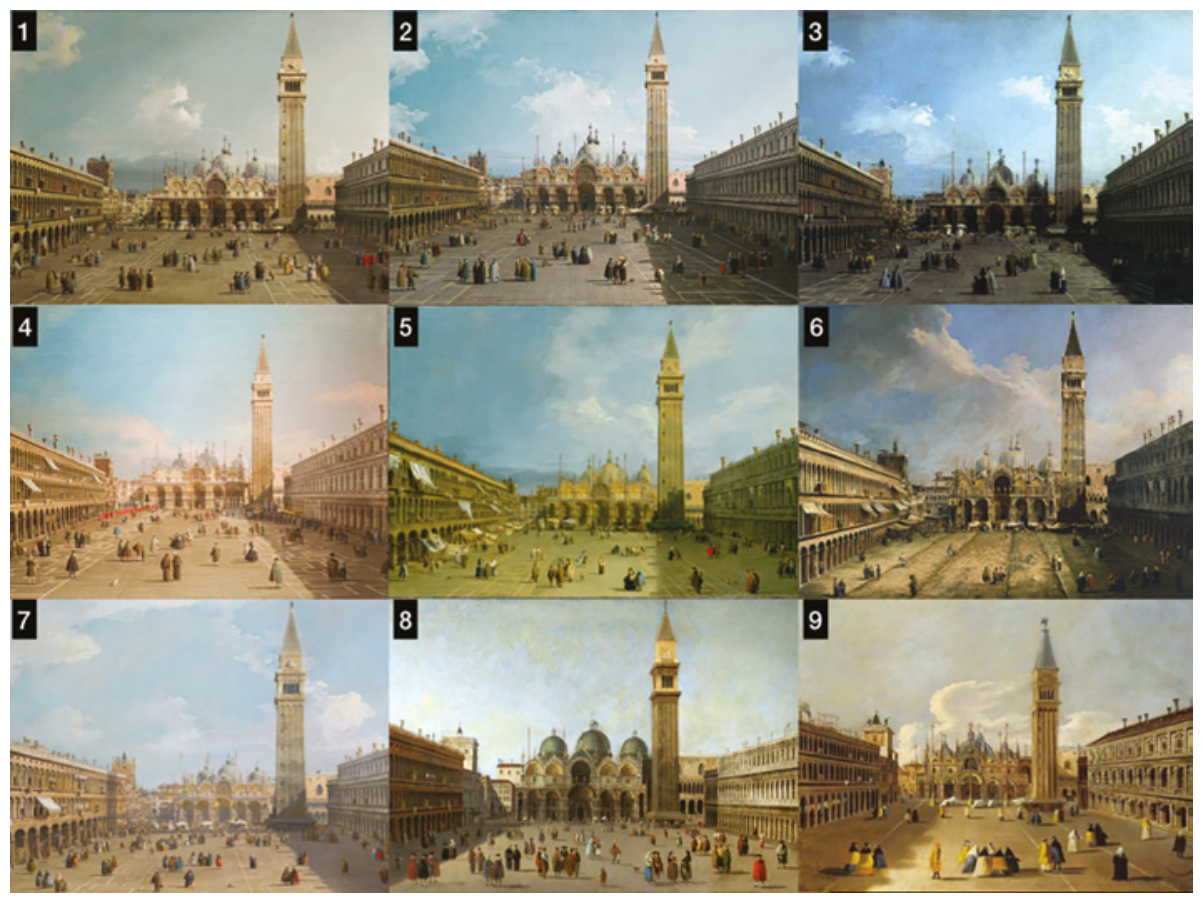

Figure 3. Nine of Canaletto's paintings of the Piazza San Marco. The numbers correspond to those in 2 . Table 1 provides information about the provenance of the paintings among other details.

representations of the paintings as far as brightness and colour are concerned, because images were obtained from different websites. Most images were obtained from museums and Sotheby's websites, guaranteeing high reproductive quality.

Figure 4 shows a painting of Canaletto together with analysed details. The painting is numbered 1 in Tables 1 and 2. The tables provide information on date of painting, ownership, accuracy of vanishing points and shadows, eye level, and computed heights of the Campanile, the Basilica and human figures. Conspicuous is the high eye level of the painter of about $9 \mathrm{~m}$ above the Piazza. The high eye level is characteristic for a large number of paintings of Canaletto and his contemporaries. The computed height of the Campanile shows that it is painted in a photorealistic ratio relative to the Procuratie Vecchie. The Basilica, however, is not. It is painted about $42 \%$ too large. The computed width of the geometric patterns on the Piazza accurately reflects their actual width. Perspective lines along the various buildings and patterns converge in three vanishing points, precisely lying on the horizon. Comparison of Fig. 4 with Figs 1 and 2 shows that the vanishing points are incorrectly placed on the Basilica. Their distribution is symmetric instead of asymmetric. The position 


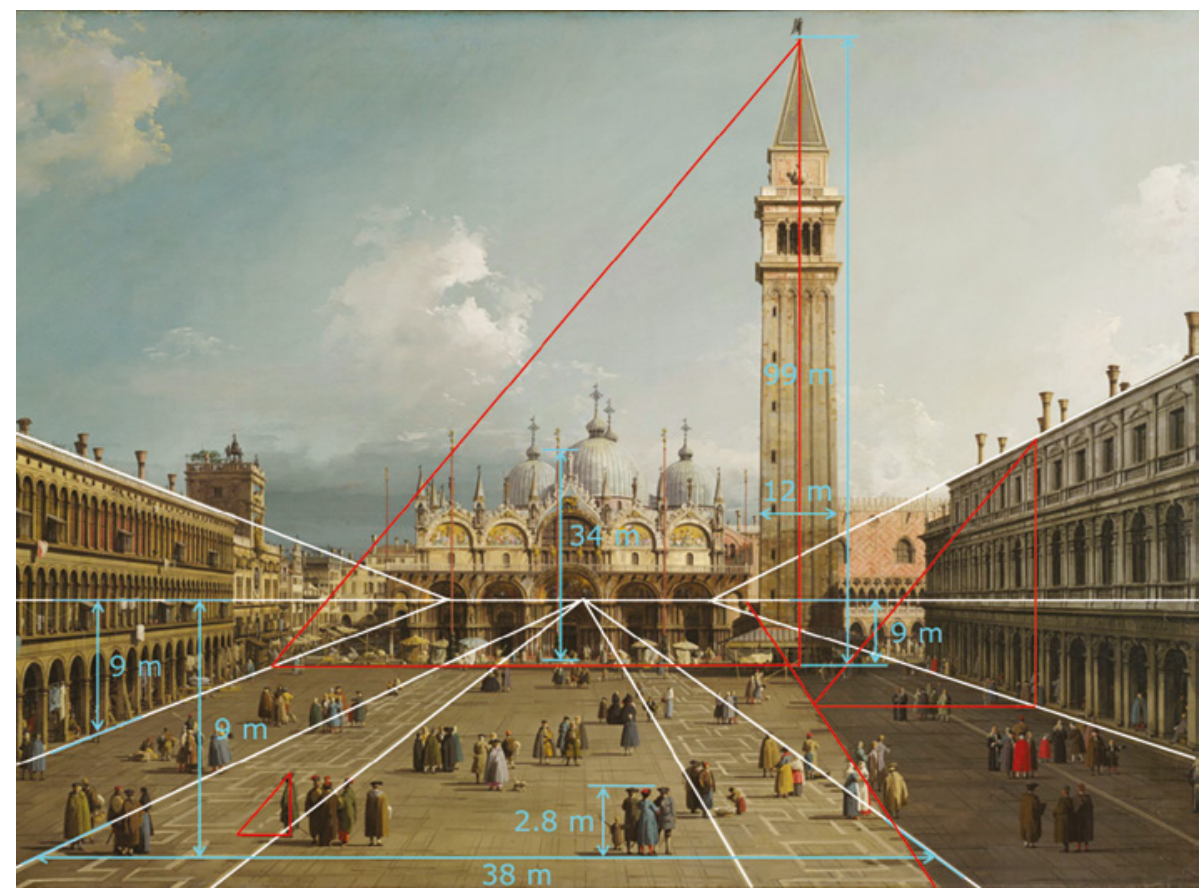

Figure 4. Piazza San Marco with the Basilica, painted by Canaletto between 1730 and 1734 . The painting is on display in the Fogg Museum (Harvard Art Museums), Cambridge, MA, USA. Added white lines indicate perspective directions for the Procuratie Vecchie (left), the geometric patterns (middle) and the Procuratie Nuove (right). The added red line and triangles were used for the analysis of shadows. Computed eye level, heights of the Campanile, Basilica and human figures, and outer width of the patterns are related to heights of the floors of the Procuratie Vecchie buildings shown in Fig. 2.

of the middle vanishing point on the central arch suggests that the viewpoint is close to the south strip of the geometric patterns. If true, the middle flagpole should be positioned beyond the north side of the central arch. However, it is placed near the centre of the arch, showing that vanishing point and flagpole provide inconsistent information about the viewpoint. The perspective lines and vanishing points drawn in the painting of Fig. 4 show that Canaletto painted the Piazza San Marco with great precision. A conspicuous detail is that the outer flagpoles are painted outside of the geometric patterns instead of at their centres. Figure 4 also shows that the flagpoles are taller than the central arch of the Basilica in the paintings, whereas both are about equally tall in the photograph of Fig. 2. The flagpoles are too tall in all the analysed paintings. Another conspicuous detail is the height of human figures in the painting. The human figures are as tall as about $2.8 \mathrm{~m}$ (Table 2), whereas heights of 1.60 to 1.70 $\mathrm{m}$ would have been appropriate for (Italian) people in the eighteenth century. 
Table 1.

Details of paintings by Canaletto of the Piazza San Marco. The paintings are ordered by the quality of perspective lines and number of vanishing points.

\begin{tabular}{lllll}
\hline Number & Year & Owner & \# vanishing points & Shadows \\
\hline 1 & $1730-34$ & Fogg Museum, Cambridge, USA & 3 points & $\mathrm{Pi}$ Cc \\
2 & $1738-39$ & Private Collection, Sotheby's 2013 & 3 points & $\mathrm{Pi}$ Cc \\
3 & 1740 & Musée Jacquemart-André, Paris & 3 points & $\mathrm{Pc}$ Ci \\
4 & 1723 & Instituto Ricardo Brennand, Recife & 3 points & $\mathrm{Pi}$ Ci \\
5 & $1727-29$ & Metropolitan Museum of Art, New York & 3 points: 1too high & $\mathrm{Pi}$ Cc \\
6 & 1723 & Museo Thyssen-Bornemisza, Madrid & 3 points: 1too high & $\mathrm{Pc}$ Ca \\
7 & $1730 s$ & Private Collection, Sotheby's 2014 & 2 points & $\mathrm{Pc}$ Cc \\
8 & - & Thirlestane Castle, Lauder, Scotland & 1 point & $\mathrm{Pc}$ Cc; \\
9 & - & Private Coll. (... with elegant figures...) & 1 point & $\mathrm{Pc}$ Cc; \\
\hline
\end{tabular}

Codes for shadows: $\mathrm{P}=$ Procuratie, $\mathrm{c}=$ consistent, $\mathrm{i}=$ inconsistent;

$\mathrm{C}=$ Campanile, $\mathrm{a}=$ absent, $*=$ impossible direction.

Table 2.

Computed sizes of buildings and people in Canaletto's paintings of the Piazza San Marco. Heights of eye level, Campanile (C.), Basilica (B.), human figures (F.), and width of geometric patterns are related to the height of buildings along the Procuratie Vecchie. Numbers refer to the paintings in Table 1.

\begin{tabular}{lcllll}
\hline Number & Eye level & Height C. & Height B. & Height F. & Width P. \\
\hline 1 & $9 \mathrm{~m}$ & $99 \mathrm{~m}$ & $34 \mathrm{~m}$ & $2.8 \mathrm{~m}$ & $38 \mathrm{~m}$ \\
2 & $9 \mathrm{~m}$ & $81 \mathrm{~m}$ & $28 \mathrm{~m}$ & $2.3 \mathrm{~m}$ & $50 \mathrm{~m}$ \\
3 & $6 \mathrm{~m}$ & $85 \mathrm{~m}$ & $28 \mathrm{~m}$ & $2.4 \mathrm{~m}$ & $36 \mathrm{~m}$ \\
4 & $7 \mathrm{~m}$ & $77 \mathrm{~m}$ & $26 \mathrm{~m}$ & $2.6 \mathrm{~m}$ & $49 \mathrm{~m}$ \\
5 & $8 \mathrm{~m}$ & $99 \mathrm{~m}$ & $32 \mathrm{~m}$ & $2.6 \mathrm{~m}$ & $40 \mathrm{~m}$ \\
6 & $11 \mathrm{~m}$ & $79 \mathrm{~m}$ & $27 \mathrm{~m}$ & $2.6 \mathrm{~m}$ & - \\
7 & $11 \mathrm{~m}$ & $98 \mathrm{~m}$ & $26 \mathrm{~m}$ & $2.7 \mathrm{~m}$ & $34 \mathrm{~m}$ \\
8 & $9 \mathrm{~m}$ & $75 \mathrm{~m}$ & $32 \mathrm{~m}$ & $3.7 \mathrm{~m}$ & - \\
9 & $8 \mathrm{~m}$ & $49 \mathrm{~m}$ & $21 \mathrm{~m}$ & $2.6 \mathrm{~m}$ & - \\
Mean & & $82 \mathrm{~m}$ & $28 \mathrm{~m}$ & $2.7 \mathrm{~m}$ & $41 \mathrm{~m}$ \\
\hline
\end{tabular}

Precise perspective lines and vanishing points are characteristic for Canaletto's paintings of the Piazza San Marco. The upper six paintings of Table 1 are very similar in that all contain precise perspective lines converging in three vanishing points. Eye level and, thus, the viewpoint of these paintings varies considerably (Table 2) from 6 to $11 \mathrm{~m}$. The Campanile is generally painted 


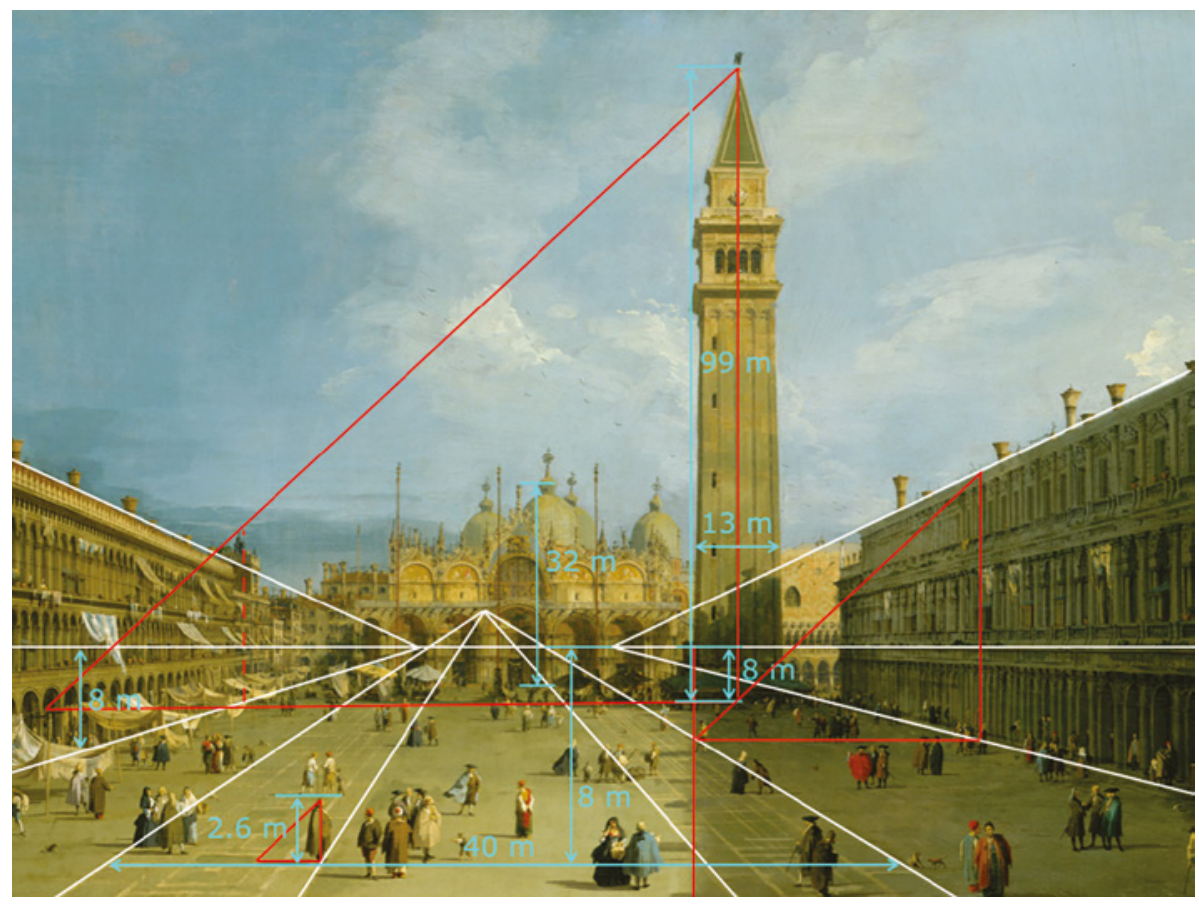

Figure 5. Piazza San Marco with the Basilica, painted by Canaletto between 1727 and 1729 . The painting is owned by the Metropolitan Museum of Art, New York City. Added white lines indicate perspective directions for the Procuratie Vecchie (left), the geometric patterns (middle) and the Procuratie Nuove (right). Perspective lines for the patterns on the Piazza meet above the horizon. The added red line and triangles were used for the analysis of shadows. Computed eye level, heights of the Campanile, Basilica and human figures, and outer width of the patterns are related to heights of the floors of the Procuratie Vecchie buildings shown in Fig. 2.

too small, the Basilica too large and the geometric patterns too wide (Table 2). The human figures are overly large in all the paintings.

Figure 5 shows a painting (painting 5 in Tables 1 and 2) whose perspective lines and vanishing points show an inaccuracy that has not been remarked in the book that accompanied the first exhibition of the work of Canaletto held in the United States (Baetjer and Links, 1989) nor on the museum's website. The painting is on display in the Metropolitan Museum of Art, New York City. The two outer vanishing points are precisely positioned on the horizon. They are located somewhat right of the flagpoles at positions similar to those shown in Fig. 2. The outer flagpoles are positioned where they should be, namely at the centres of the geometric patterns. The perspective lines of the patterns on the Piazza converge precisely in a single vanishing point too. The vanishing point, 
however, is located a few meters above eye level and the other two vanishing points.

The middle vanishing point and the middle flagpole are both placed at the north side of the central arch. The position of both is consistent with a viewpoint on the central axis of the geometric patterns. Computed sizes show that the Campanile is painted in the correct ratio with the Procuratie Vecchie. The Basilica is about $30 \%$ too high. The human figures are about $2.6 \mathrm{~m}$ tall in the painting (Table 2). Another painting of Canaletto with two vanishing points on the horizon and one point above the horizon is on display at the Museo Thyssen-Bornemisza in Madrid (painting 6 in Fig. 3 and Tables 1 and 2). This early painting (1723) shows the Piazza San Marco without the geometric patterns. It shows the brick pavement that was replaced with the more complex geometrical pavement design in 1723. In fact, a few unfinished geometrical patterns are visible on the painting. The Piazza in the painting contains a few perspective lines converging in a single vanishing point. Horizontally, the point lies asymmetrically in between the two other vanishing points. Vertically, however, it is positioned above eye level and the other vanishing points. Eye level $(11 \mathrm{~m})$ is a few meters higher than in the other paintings. The human figures are about $2.6 \mathrm{~m}$ tall in the painting (Table 2).

In one of the analysed paintings the Piazza shows a type of perspective that seems hard to reconcile with the expertise of Canaletto (Fig. 6 and painting 7 in Tables 1 and 2). The painting was sold by Sotheby's in 2014 to a private collector. The painted scene contains just two vanishing points. Perspective lines for the Procuratie Vecchie and the geometric patterns converge precisely in a single vanishing point. Incorrectly, the painter (Canaletto?) assumed that the geometric patterns are parallel to the Procuratie Vecchie. Perspective lines for the Procuratie Nuove converge in a second vanishing point. Both vanishing points lie accurately at eye level. Distance between the two vanishing points is smaller than the distance between adjacent vanishing points in paintings 1 to 6 and the photograph in Fig. 2. Sizes of the Campanile, the Basilica and the geometric patterns are relatively accurate in relation to that of the Procuratie Vecchie. Sizes of the human figures are comparable to those in the other paintings.

The current analyses include two paintings, maybe by Canaletto, but more likely by unknown artists who painted Piazza San Marco in the manner of Canaletto. Figure 7 (painting 8 in Tables 1 and 2) shows the veduta that belongs to the collection of Thirlestane Castle in Lauder, south of Edinburgh. Different from Canaletto's other paintings of the Piazza, all perspective lines are directed to a single vanishing point located at the central arch of San Marco. The single vanishing point implies that the artist assumed the Piazza to be rectangular of shape. Perspective lines and vanishing point are highly precise. The Campanile is short in comparison with the height of buildings of the 


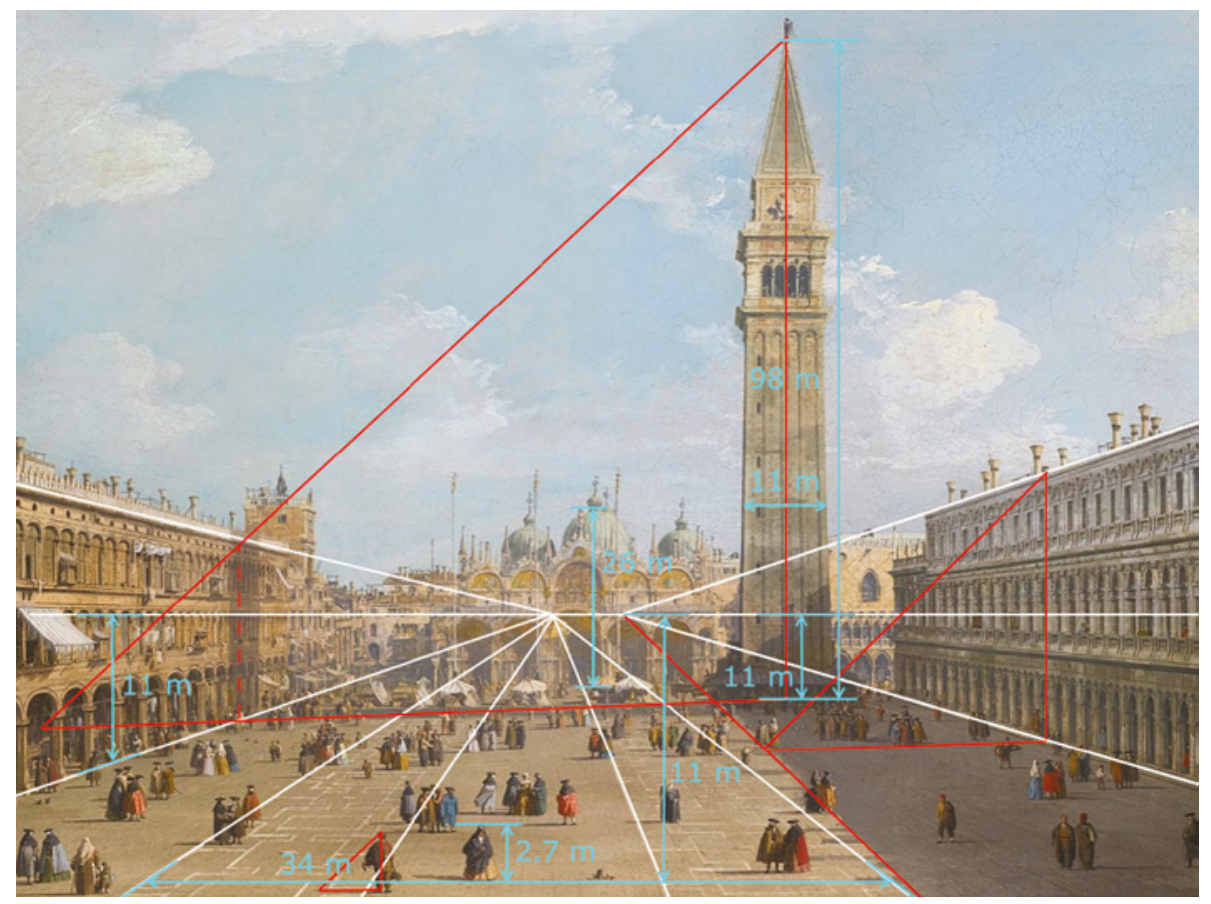

Figure 6. Piazza San Marco with the Basilica, attributed to Canaletto. The painting is part of a private collection. Added white lines indicate perspective directions for the Procuratie Vecchie (left), the geometric patterns (middle) and the Procuratie Nuove (right). Perspective directions for Procuratie Vecchie and Piazza patterns converge to a common vanishing point. The added red line and triangles were used for the analysis of shadows. Computed eye level, heights of the Campanile, Basilica and human figures, and outer width of the patterns are related to heights of the floors of the Procuratie Vecchie buildings shown in Fig. 2.

Procuratie Vecchie. On the other hand, the Basilica San Marco is overly tall. The human figures are large too in relation to figures in the other paintings. Their computed height of $3.7 \mathrm{~m}$ is about $1 \mathrm{~m}$ taller than the mean height of people in all paintings (Table 2). The second painting is called "A view of the Piazza San Marco with elegant figures dressed in carnival costumes" and is part of a private collection (painting 9 in Fig. 3 and Tables 1 and 2). The perspective quality is fairly unimpressive. Perspective lines do not converge in a single vanishing point but rather in a region near the central arch of the Basilica. Furthermore, eye level on the left side of the painting is considerably lower than on the right side. It is about $7 \mathrm{~m}$ above the Piazza on the left side and about $9 \mathrm{~m}$ on the right side. The Campanile has been painted much too short in relation to the other buildings. Its computed height is just half the Campanile's height in reality (Table 2). 


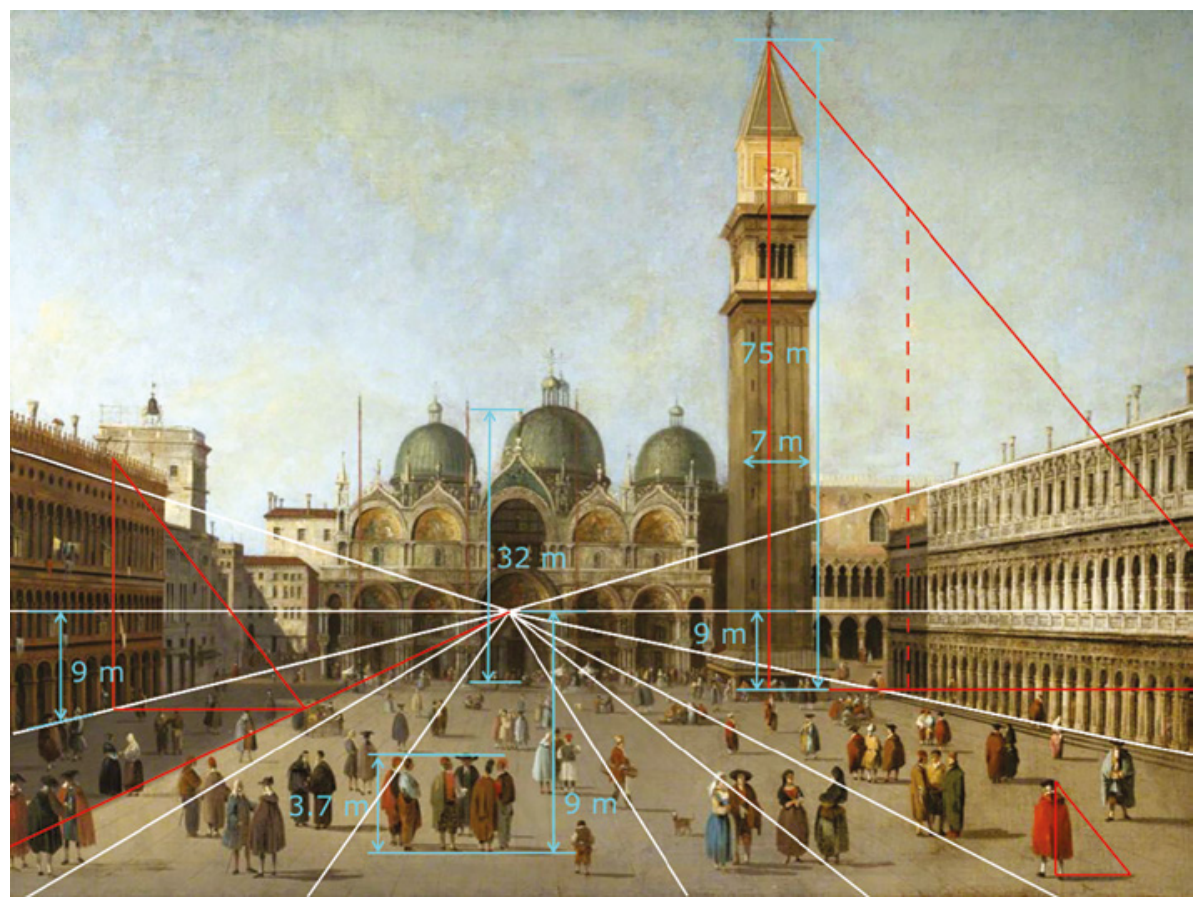

Figure 7. Piazza San Marco with the Basilica, probably painted by an unknown artist. The painting is owned by Thirlestane Castle, Lauder, Scotland. Added white lines indicate perspective directions for the Procuratie Vecchie (left), bricks of the pavement (middle) and the Procuratie Nuove (right). The added red line indicates a perspective line for the shadow of the Procuratie Vecchie. All perspective lines converge to a single vanishing point. The added red line and triangles were used for the analysis of shadows. Computed eye level, heights of the Campanile, Basilica and human figures, and outer width of the patterns are related to heights of the floors of the Procuratie Vecchie buildings shown in Fig. 2.

\section{Analysis of Shadows}

Shadows are an instriguing aspect of the analysed paintings. The perspective quality of shadows has been analysed in two ways. Perspectives lines were drawn along shadows of the Procuratie on the Piazza. Shadows are called consistent if perspective lines of shadows intersect the horizon at the same location as the vanishing point of the buildings. Shadows are called inconsistent if perspective lines of shadows intersect the horizon at another location. Table 1 shows the results for all the paintings. Remarkably, perspectives lines of shadows are inconsistent in a number of paintings whose perspective quality is otherwise excellent (paintings 1,2,4). On the other hand, perspectives lines of shadows are consistent in a number of paintings whose perspective quality is inaccurate (paintings 7 and 8 ) or inferior (painting 9). The perspective quality 
of shadows was further analysed by comparing the length and direction of shadows cast by one of the Procuratie, the Campanile and one of the human figures. Hypotenuses of triangles formed by objects and their shadows indicate the direction of the sun. Triangles should be similar for the Procuratie, the Campanile and human figures. The triangles are similar for the Procuratie and human figures in all the paintings. The triangles along the Campanile show that shadows of the Campanile deviate in a number of paintings. Shadows of the Campanile can be grouped in three classes, namely, consistent or inconsistent with the other shadows or absent (Table 1). Figures 4, 5, 6 and 7 show examples of consistent shadows (paintings 1, 2, 5, 7, 8 and 9 in Table 1). Shadows are inconsistent in paintings 3 and 4 of Table 1 . The shadow of the Campanile is oriented in depth and covers a part of the Basilica San Marco in these paintings. A shadow is absent in painting 6. Although shadows of the Campanile are consistent in a number of paintings, they are not completely satisfactory. They are consistent in direction but not in length. Figures 4 and 5 show rather thin shadows of the Campanile on the Piazza San Marco. Shadows on the Procuratie Vecchie, however, are absent in Fig. 5 where they should be present. It is even defendable that the Campanile does not cast a shadow at all in the paintings. An alternative interpretation is that the flagpoles, human figures, tents and stalls cause the depicted shadows on the Piazza. Close examination of Figs 4 and 5 shows that tents and stalls are painted in full sunlight. Shadows of the Campanile are much broader and clearly visible on both the Piazza San Marco and the Procuratie Vecchie in Fig. 6. Curiously, this painting combines incorrect vanishing points with correct shadows as far as perspective is concerned. This means that the painter was skilled in perspective but unfamiliar with the geometry of the Piazza.

The human figures cast shadows parallel to the frontal plane and, thus, without a depth component in all the paintings of Canaletto. Shadows to the left side of the figures in 7 of the 9 paintings imply a solar azimuth of about $150^{\circ}$ (close to SSE as is shown by the compass rose in Fig. 2). Furthermore, lengths of the shadows suggest solar altitudes of about $45^{\circ}$. This combination of azimuth and altitude occurs in Venice on March 30 at about 11:00 am and again on September 12 at about 11:45 am. This means that, according to the shadows, all 7 paintings show human figures in spring or autumn at the end of the morning. Two of the analysed paintings show shadows to the right side of the human figures (Fig. 7 and paintings 8 and 9 in Tables 1 and 2). The shadows are oriented away from the Procuratie Vecchie. The shadows to the right side are impossible because of the orientation of the Piazza San Marco. The shadows suggest a solar azimuth of about $330^{\circ}$ (close to NNW as is shown by the compass rose in Fig. 2). The most northwest direction of the sun in Venice is about $300^{\circ}$ (close to WNW) at sunset on June 21. Thus, the shadows suggest the sun to be oriented about $30^{\circ}$ more to the north than it ever 
is during its yearly cycle. Furthermore, lengths of the shadows suggest a solar altitude of about $45^{\circ}$. This altitude occurs at about 10:00 am and 16:30 pm on June 21 in Venice. Solar azimuths are $102^{\circ}$ and $258^{\circ}$ at those times and dates, respectively, remote from the suggested azimuth of $330^{\circ}$. In conclusion, the combination of solar azimuth and altitude suggested by the shadows in paintings 8 and 9, is impossible at any time and day of the year.

\section{Discussion}

Canaletto is the most celebrated view painter of eighteenth-century Venice (Whitaker and Razzall, 2017). He was particularly popular with British royalty and nobility who visited the city on their Grand Tour. He was so popular that he was asked to work in London later in his career. The paintings of Canaletto are regarded as so photorealistic and accurate that physicists of the Institute of Atmospheric Sciences and Climate in Padova studied the water level in Venice in his paintings (Camuffo and Sturaro, 2003; Camuffo et al., 2017). Canaletto's paintings provided evidence for a relative rise of sea level of about $60 \mathrm{~cm}$ since the time of Canaletto. It may not be accidental that Venice is currently experiencing the worst flooding in its history.

Apart from small displacements along the horizon, vanishing points and perspective lines are almost flawless in four of Canaletto's paintings of Piazza San Marco analysed in this study. The paintings were produced between 1730 and 1740, except for the painting that is on display in the Ricardo Brennand Institute in Recife, which is dated 1723. The scene on the painting, however, casts some doubt on the date. The painting shows an Easter or Holy Week procession on the Piazza with the geometric design in a completed state. The paving of the Piazza, however, was replaced between 1723 and 1734. In 1723, the pavement consisted of bricks laid in a herringbone pattern. Bands of light-coloured stone ran parallel to the long axis of the Piazza. The bands can be seen on the Thyssen-Bornemisza painting that is also dated 1723. The geometric design was finished not earlier than between 1725 and 1727, which suggests that the Ricardo Brennand painting may have been antedated.

Most painters of vedute in the eighteenth century applied one-point perspective for creating depth in scenes. Positioning three vanishing points on the horizon near the centre of a painting, as Canaletto did, is exceptional. The four paintings with almost perfect perspective lines and vanishing points show that Canaletto had detailed knowledge of the layout of the Piazza and was highly skillful in projecting its uncommon geometry on the two-dimensional canvas. Given Canaletto's expertise, it is remarkable that five of the Piazza paintings show peculiar perspective flaws. The painting hanging at the Metropolitan Museum of Art in New York (Fig. 5) contains a flaw that is also present in the 
painting of Museo Thyssen-Bornemisza in Madrid. The flaw is that the central vanishing point is positioned above the horizon. Both paintings were completed in the 1720s. The explanation for the flaw may be that at that time Canaletto was still in the phase of perfecting perspective in his paintings. There are three paintings showing other flaws in perspective. One painting is dated in the 1730s, the period in which Canaletto painted almost perfect perspective lines and vanishing points. The painting (Fig. 6), attributed to Canaletto, was once owned by the Douglas Pennant family and kept at the Penrhyn estate in Bangor (Wales). In 2009 it was sold to a European collector who in turn sold it for $£ 5.4 \mathrm{~m}$ in 2013 . The flaw in perspective consists of the amalgamation of vanishing points for the Procuratie Vecchie and the geometric patterns. The single vanishing point indicates that the painter assumed that the geometric patterns were oriented parallel to the Procuratie Vecchie. It is hard to attribute the inaccurate but precise vanishing points to inattention or sloppiness. Considering that other concurrent paintings show Canaletto's knowledge of the Piazza's layout, the incorrect vanishing point casts some doubt on the painting's authenticity. The applied perspective is very unrealistic in two paintings (Fig. 7 and paintings 8 and 9 in Tables 1 and 2). Both the flawed perspective and impossible shadows make it hard to believe that the painters of these pieces had ever visited the Piazza San Marco.

Canaletto is long thought to have used a camera obscura to achieve accuracy in his work. Hockney and Gayford (2016) discussed the painting of Piazza San Marco on view at the Metropolitan Museum of Art (Fig. 5). They praised Canaletto's craftsmanship. They concluded that he used a camera obscura for help with perspective. This view was challenged by conservators of the Royal Collection Trust (Whitaker and Razzall, 2017). The conservators used infrared photography of the artist's drawings and revealed "details of his working methods for the first time." Analysis of the photographs casts doubt on the long-held view that Canaletto used a camera for construing perspective in his paintings. The discoveries were made during research for the exhibition named "Canaletto \& the Art of Venice", held at The Queen's Gallery of Buckingham Palace in London. According to the Royal Collection Trust, the infrared photography showed that Canaletto was not tracing the outlines of buildings in the open air but was carefully plotting out the scene with pencil and ruler in the studio. The level of precision and accuracy of perspective lines and vanishing points, particularly of paintings 1 to 4 , supports the conclusion of Whitaker and Razzall (2017). A small camera obscura equipped with a primitive lens seems inappropriate for sketching the Piazza's perspective geometry with such a high accuracy (Baetjer and Links, 1989). Canaletto, being the owner of a camera obscura, may have used the camera for studying the composition of a painting. It is more likely that Canaletto used a floor plan for positioning the vanishing points in his paintings. 


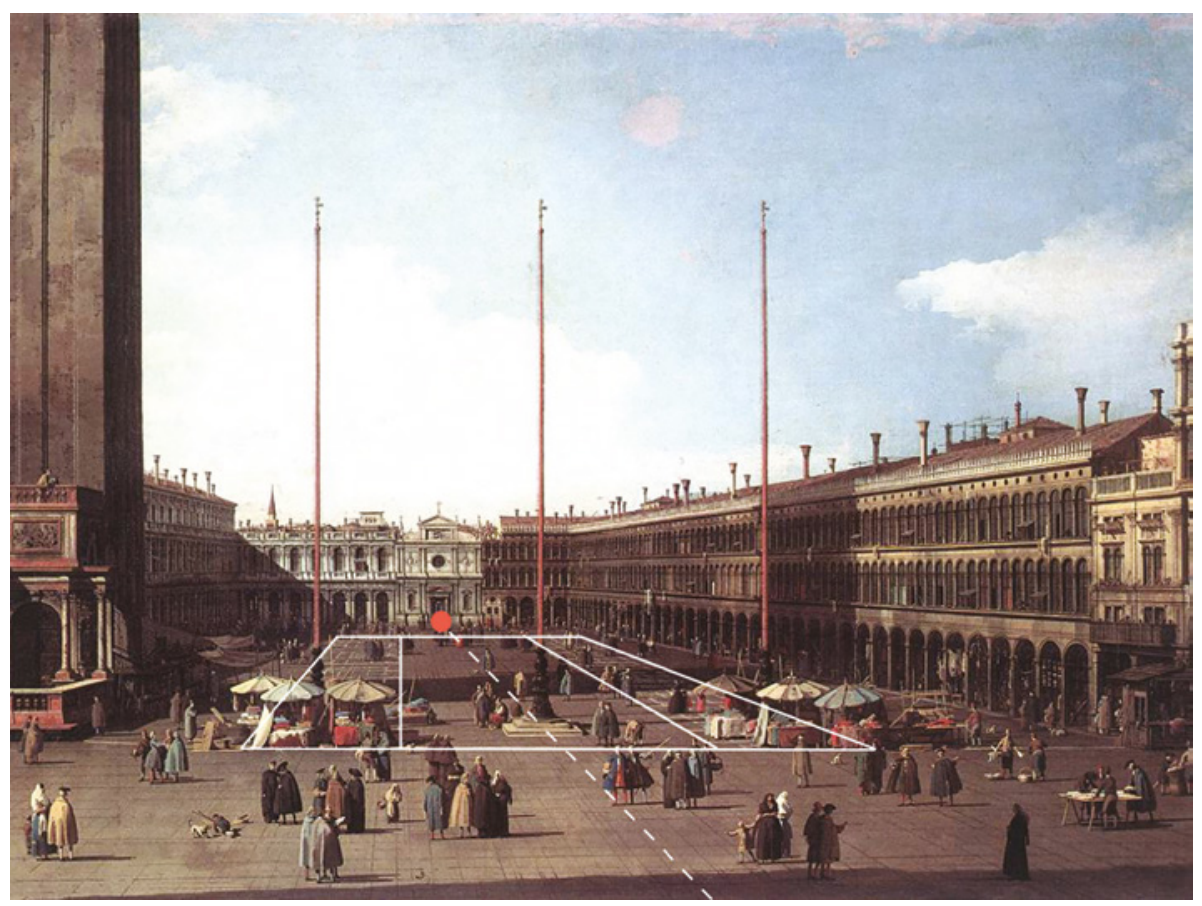

Figure 8. Piazza San Marco, looking toward Ala Napoleonica. It was painted by Canaletto in 1735. The painting is owned by Galleria Corsini, Roma. The viewing position is in front of San Marco with the Campanile on the left side. The painting shows the church San Geminiano behind the (dashed) central line of the geometric patterns marked by the added white lines. The location of the red dot is identical to the position of the red dot in Fig. 1.

A conspicuous aspect of Canaletto's paintings of Piazza San Marco is the high viewpoints. The viewpoints were located at the west side of the Piazza near the central axis of the geometric patterns at heights of 7 to $11 \mathrm{~m}$ above the pavement. In the eighteenth century a church was located at this side of the Piazza. Canaletto painted the church, called San Geminiano, himself in 1735 (Fig. 8). The church was demolished in 1810 and replaced by the Ala Napoleonica. As Fig. 8 shows, the church did not have a loggia or balcony. The variation of viewpoints of Canaletto's paintings are hard to reconcile with openings in the front of the church. The viewpoints varied between 7 and $11 \mathrm{~m}$ above the pavement. The rose window was the only opening above $6 \mathrm{~m}$. Actually, its height was about 12 to $14 \mathrm{~m}$ above the pavement and, thus, higher than the viewpoints of the paintings. There are three possibilities for how Canaletto achieved the variation in viewpoints. One possibility is that Canaletto used a scaffold in front of the church. To my knowledge, there are no reports of Canaletto making use of scaffolds in the literature. Another possibility is that he made sketches from the rose window and transposed the sketches to other 
viewpoints in his studio. The latter method would have been possible if he used a floor plan for the construction of appropriate vanishing points from a specific viewpoint. Working with rulers and pencils as well as painting from sketches in a studio was common practice in the eighteenth century. En plein air painting was hardly possible at the time, because paint in tubes first came onto the market after 1841. A third possibility is that he made sketches from the colonnade adjacent to the San Geminiano (at, say, the $7 \mathrm{~m}$ height). Getting up to $11 \mathrm{~m}$ by this means would, however, be quite a stretch, although not at all impossible if Canaletto had built some kind of platform, as was common practice for painters of the Italian Renaissance.

Shadows are another interesting aspect of the paintings. A recent study showed that Canaletto had considerable difficulty with shadows in depth (Wijntjes and de Ridder, 2014). A common trick to avoid shadow perspective problems is to paint the shadows parallel to the canvas. Apparently, Canaletto employed the same trick for paintings of the Piazza San Marco. All human figures are accompanied by stereotypical shadows to the left or right side in the analysed paintings. Shadows to the left side in 7 of the 9 analysed paintings imply that these paintings depict the Piazza in the morning between about 10 and 11 o'clock. None of the paintings shows the Piazza either early in the morning or in the afternoon. Shadows to the right side in two of the paintings are impossible. It seems unlikely that Canaletto painted the works.

Table 2 shows that both the Campanile and Basilica have various sizes in the paintings. Canaletto painted the Campanile accurately or too short relative to the Procuratie in all the analysed paintings, whereas he always painted the Basilica too large. The reason may be that Canaletto intended to emphasize the Basilica as the most important building in the painting. Pepperell and colleagues explain non-photorealistic sizes in paintings in terms of perceived size in the central and peripheral visual field (Baldwin et al., 2014; Pepperell and Haertel, 2014). The explanation, however, is hard to reconcile with the fact that viewers usually make eye movements when they are viewing paintings. Size of the human figures is another conspicuous detail of the analysed paintings. Although the human figures are gigantic, they look so natural that their extreme size has gone unnoticed until now. In view of Canaletto's accuracy there are two possibilities for the large sizes: either he painted the human figure this large to achieve a certain effect or other artists may have painted the human figures. Hockney and Gayford (2016) discussed that "rushing" perspective tends to push scenes away from the viewer. Overly large human figures may nullify this effect and show the Piazza more intimate than it is. The second possibility is that other artists or apprentices may have added the human figures and other details such as shadows to the paintings. It is known that Canaletto was a productive artist who acquired many commissions and used the assistance of pupils to get the work done. 
The combination of accurate perspective lines and vanishing points, on the one hand, and inaccurate sizes of buildings and human figures as well as the stereotypical shadows, on the other hand, may reflect the way in which the paintings have been produced. Canaletto is known to have managed a studio in which his father, Bernardo Canal, and his nephew, Bernardo Bellotto, and others assisted in the production of paintings (Baetjer and Links, 1989). Differences in perspective quality suggest that shadows and human figures were not painted by Canaletto but were added by his relatives and pupils.

\section{Conclusion}

The current analysis shows that Canaletto had detailed knowledge of the layout of the Piazza and was highly skillful in projecting its uncommon geometry on the canvas. The paintings are not photorealistic, making it unlikely that he used optical projection tools. Canaletto varied the sizes of buildings and human figures in different paintings. He used high viewpoints, which are difficult to reconcile with accessible locations at that time.

\section{References}

Baetjer, K. and Links, J. G. (1989). Canaletto. Metropolitan Museum of Arts, New York, NY, USA.

Baldwin, J., Burleigh, A. and Pepperell, R. (2014). Comparing artistic and geometrical perspective depictions of space in the visual field. i-Perception, 5, 536-547.

Camuffo, D. and Sturaro, G. (2003). Sixty-cm submersion of Venice discovered thanks to Canaletto's paintings. Climatic Change, 58, 333-343.

Camuffo, D., Bertolin, C. and Schenal, P. (2017). A novel proxy and the sea level rise in Venice, Italy, from 1350 to 2014. Climatic Change, 143, 73-86.

Cursi, L. V. (2002). Gaspare Vanvitelli e le Origini del Vedutismo. Viviani Arte, Rome, Italy.

Erkelens, C. J. (2015). The perspective structure of visual space. i-Perception, 6(5), 1-13.

Erkelens, C. J. (2016). Equidistant intervals in perspective photographs and paintings. i-Perception, 7(4), 1-14.

Erkelens, C. J. (2017). Perspective space as a model for distance and size perception. $i$-Perception, 8, 1-20.

Facos, M. (2011). An Introduction to Nineteenth-Century Art. Routledge, London, UK.

Hockney, D. (2001). Secret Knowledge: Rediscovering the Lost Techniques of the Old Masters. Thames and Hudson, London, UK.

Hockney, D. and Gayford, M. (2016). A History of Pictures. Thames and Hudson, London, UK. Kemp, M. (1990). The Science of Art: Optical Themes in Western Art from Brunelleschi to Seurat. Yale University Press, New Haven, CT, USA.

Lüthy, C. (2005). Hockney's Secret Knowledge, Vanvitelli's Camera Obscura. Early Sci. Med., 10, 315-339.

Pepperell, R. and Haertel, M. (2014). Do artists use linear perspective to depict visual space? Perception, 43, 395-416. 
Steadman, P. (2001). Vermeer's Camera: Uncovering the Truth behind the Masterpieces. Oxford University Press, Oxford, UK.

Whitaker, L. and Razzall, R. (2017). Canaletto and the Art of Venice. Royal Collection Trust, London, UK.

Wijntjes, M. W. A. and de Ridder, H. (2014). Shading and shadowing on Canaletto's Piazza San Marco, Human Vision and Electronic Imaging XIX, 901415. Proceedings of SPIE-IS\&T Electronic Imaging, San Francisco, CA, B. E. Rogowitz, T. N. Pappas and H. de Ridder (Eds). doi: 10.1117/12.2047854. 